\title{
The History of Colonial Science and Medicine in British India: Centre-Periphery Perspective
}

\author{
Rahul Bhaumik*
}

(Received 02 June 2016)

\begin{abstract}
The paper focuses on the various issues/models relating to nature of diffusion of scientific ideas and practices during the colonial period. In the process, Basalla's three phase model, the character of transmission and absorption of scientific knowledge in the period from center to non-European peripheries, and opinion of different scholars on them are critically examined. Efforts are also made to articulate a new perspective on how local issues developed within certain colonial condition often convincingly contributed to the actual creation of the western science and or medicine.
\end{abstract}

Key Words: Basalla's model, Colonial condition, Colonial periphery, Imperial metropole, Western science and medicine.

\section{INTRODUCTION}

The history of colonial science and medicine in British India is nowadays a rapidly expanding body of scholarship. It is not only increasingly attracting the attention of scholars from a range of disciplinary locations, but has also extended the limit of previous history writings on colonial/imperial scientific disciplines. In recent years, as the varied themes and perspectives have emerged, the historiography has become more fresh and proliferative and therefore it is growingly difficult to identify any single framework for writing the history of colonial science and medicine. Drawing on this burgeoning field of scholarship, the present paper is an attempt to study the history of science and medicine in British India and in doing so it particularly aims to engage with various theoretical positions on the relationship between the 'imperial metropole' and 'colonial periphery'. The centre-periphery relationship model was first employed in the 1950s and 1960s in disciplines such as economic and political theory, in a little while its use being encouraged in the history of Western science and medicine. In the field of history, the standard version of this model suggested that there was centre of science and medicine in the West from where scientific knowledge came to be diffused and found its place in the non-Western world. In view of that, the major characteristic feature of the periphery lied in its dependence upon the centre. Although, this one-way diffusionist model continued as a historiographic scheme, it certainly provoked several critiques and debates. Against this background, by critically examining the existing historiography concerning the centreperiphery relationship, this paper carries on the idea that Western science and medicine in British India was not merely an extension of metropolitan ideas and methods. This is because the modern scientific knowledge in the colony, even though often was based on significant derivation from science in the metropole, was always sensitive to the local condition and willing to adapt, modify,

\footnotetext{
* Research Scholar, Department of History, Jadavpur University, Kolkata: 700032. Email: rahul_joy1981@yahoo.com
} 
and even sometimes deviate from their original Western epistemology on the concerned subject. Obviously, this had to be done in response to the needs and exigencies of the locale. However, before drawing any conclusion, it will be pertinent to elaborately discuss how diversely and in what perspectives the scholars of colonial science and medicine employed the notion of 'imperial metropole' and 'colonial periphery'.

\section{George Basalla's Three-Phase Model}

It is Anglo-American historian George Basalla, who in his seminal 1967 essay first propounds a three-tier model of the 'spread' of modern science from the West to the non-Western cultures (Basalla, 1967). His contention is as follows:

In the Phase One of the diffusion process, non-scientific societies served only as passive sources of data for the development of science in European country. In this period, European explorers, travellers, missionaries and other amateurs used to visit the new land, survey and collect its flora and fauna, study its physical features and then take the results of their works back to Europe.

Phase Two is marked by a period of 'colonial science' when a larger number of scientists were involved in the enterprise and the range of activity expanded considerably. In this era of 'dependent science', scientific work was carried out by transplanted European colonists or settlers or else by acculturated indigenes of the territory under consideration who saw themselves as dependents of the scientific institutions and traditions of the metropole.

Phase Three completed the process of transplantation with a struggle to achieve an independent national scientific tradition, however, based on Western professional standards.

What is unique in Basalla's model is that it does not confine itself to the diffusion of knowledge within Europe, but by asking how 'modern' science and medicine came to be diffused from its homeland in Western Europe to the rest of the world, it provides an understanding of global transfer processes. Indeed, "Escaping from an earlier historiography of science, constructed around great men and great discoveries, it encourages us to see developments in a wider context ..." (Arnold, 1993, p. 16).

\section{Early Responses to the Tripartite ModeL}

The Eurocentric Basalla's universal model however, came to be seriously and variously challenged. The leading historian in this enterprise was Roy MacLeod. In a significant theoretical piece in the mid 1980s, he argued that the difference between metropolitan and colonial science was not always clear in Basalla's typology, and emphasised that scholars should keep them analytically separate (MacLeod, 1982; 1996; 2000). According to him metropolitan science was a "way of doing science, based on learned societies, small groups of cultivators, certain conventions of discourse, and certain theoretical priorities set in eighteenth-century Western Europe" (MacLeod, 1982, p. 2). On the other end, colonial science was practiced in non-European hemisphere. It meant derivative science, which in the eyes of metropolis was a sort of 'low science', identified only with fact-gathering. But in the colonies, colonial science could mean something else. This could be intellectually derivative and also be metropolitan "in the sense of 'functional'... with values confirming the rule of 'Britannia in another world' (MacLeod, 1982, p. 2). MacLeod did not confine the metropole only to Western Europe as Basalla did. Rather, by developing his concept of a 'Moving Metropolis' he stressed on the fact that the metropolis might move over time from one location to another; because of the ever changing needs and economics of the empire and 
the forms of colonial governance. These changes, in MacLeod's view, certainly affected the scientific relations between the metropolis and the province. MacLeod also proposed an alternative framework, a five-staged progress of the so-called British imperial science between 1780 and 1939, and very modestly called for its more universal application (MacLeod, 1982, pp. 7-13).

In discussing the development of the peripheral (e.g. Australian) scientific enterprise, Ian Inkster located several minor problems with Basalla's framework which: "may not be regarded as a model until its elements are more clearly specified, and until attention has been given to the mechanisms of phase transition and the dynamics of the phases themselves" (Inkster, 1985, p. 685) ${ }^{1}$. He identified that the tripartite model did not differentiate between the scientific and technical culture that emerged in the areas of recent settlement like Australia and the areas of relatively backward economy like Japan (Inkster, 1985, p. 686). In his opinion:

\section{Basalla has very little to say about the ultimate goals of (the peripheral) science, the interests and methodologies of the scientific community (in the periphery), or its intellectual and psychological relations with the metropolitan centre (Inkster, 1985 , p. 688, parenthesis added).}

He criticised Basalla for focusing more on the marginality of colonial scientists neglecting "the tension between their metropolitan identities and their provincial situations, and their institutional and cultural divorce from the colonial setting" (Inkster, 1985, p. 684). Though, Inkster called Australian scientists as 'cosmopolitan' in the sense that: "they were spatially divorced from the centre, intellectually and mentally divorced from the provincial setting in which they lived and worked" (Inkster, 1985, p. 689), scholars commented that, Indian condition depicted altogether a different and intricate history where local setting and colonial control in concert largely influenced the scenario (Kumar, 2006, pp. 8-9).

However, as the linkage between science and colonisation in non-settler colonies like India, where small numbers of European dominated large and diverse colonised populations, was markedly different from that in white settler colonies (Adas, 1997, p. 217; Worboys, 2004, p. 218), MacLeod's and Inkster's theses concerning science in Australia are not likely to be invariably applicable to countries like British India. Nevertheless, these analytical insights inspired a number of science and medical historians of British India to critically differ with Basalla's models and propound their own lines of arguments. For example, Satpal Sangwan in his own assessment of the metropole/ colony relationship pertaining to Britain/India criticises the inadequate characterisation of Basalla's first stage. Basalla's Phase One scientists used to survey and collect data for the scientific community at home. In his book, Sangwan argues:

The British had undertaken the arduous task of scientific surveys primarily to increase the knowledge of British entrepreneurs and colonisers, not that of the scientists at home. The fact that metropolitan science also gained in the process is a by-product of their labours (Sangwan, 1991, p. 147).

Sangwan acknowledges the various achievements of 'gentlemen' scientists in the colony, who proved their abilities and effectively retained their identities despite having deep relation with the rule of profit-oriented English East India Company and research-oriented metropolitan erudite scholars (Sangwan, 1992).

V. V. Krishna too is critical of one particular hypothesis of Basalla which states that Phase Two of colonial science contains in an embryonic form,

\footnotetext{
1 Similarly, scholars argued that: "Without considerable modification this assumption is effectively blind to both history and culture, and is premised on the notion that 'pre-scientific' localities, today, start from a position similar to Europe's before scientific take-off hundreds of years ago." Chambers and Gillespie, 2000, p. 226.
} 
some of the essential features of the Phase Three. Krishna classifies the scientists settled in India from the late nineteenth to the early twentieth century into three broad categories (Krishna, 1991; 1992). For naming these categories, Krishna followed MacLeod's terminology, yet used them in different senses (MacLeod, 1982). The first category was 'gate keepers' who, following the British imperial ideal, actively endeavoured to prohibit 'Native Indian Scientists' from joining the colonial scientific enterprises. "'Gate keepers' operated on several fronts including education, industry, finance and science departments" (Krishna, 1992, p. 58). The second group was the 'scientific soldiers', European or Indian by birth, educated and trained in Britain, came to India either through government channels or commerce and served for low-status scientific jobs in the Empire (Krishna, 1992, p. 59). Krishna writes:

They had no commitment to the promotion of scientific disciplines or scientific societies, and their goal was limited to the accomplishment of their assigned tasks. When these British scientists completed their assignments or attained the age limit, they returned to their country taking with them a vast treasure of experience (Krishna, 1991, p. 92).

On the other hand, mostly 'native' Indians by race and a small number of European missionaries and Jesuits together shaped the third sort, whom Krishna identifies as 'national scientists', responsible for the growth of an independent scientific culture. As the first two categories were neither national nor independent in the true sense, Krishna delinks them from the last and refuses to accept any embryonic links between Phase Two and Phase Three. Although, Sangwan and Krishna both recognise the difficulties of discussing the transformation of Western scientific knowledge in British India in terms of Basalla's diffusionist theory, they overlook the fact that the colonial scientist was a much more critical person than they assume. Whichever stage such a scientist might belong to, the specificity of the colonial situation often made him simultaneously factgatherer and theory maker. A colonial scientist's impact might not necessarily have confined only to the peripheral world of colonial knowledge, but indeed might have modified any dominant medical idea in the West.

"Basalla's model", according to Dhruv Raina, "stimulated attempts to open up the Pandora's box of science and imperialism, but did so inadvertently" (Raina, 1999, p. 500)2. In his view, this and other Basalla-like schemes, suggest that science is a 'cultural universal' and its reception by the periphery is unproblematic (Raina, 2003, p. 159). These studies restrict their historical concern only to the implantation of modern scientific knowledge and the institutions of modern science in non-Western environments and view the non-West merely as laboratories for performance of scientific experiments (Raina, 1999, p. 498). In this context, Basalla's framework is vulnerable to the charge of Eurocentrism as it cannot accommodate cross-cultural exchanges and is preoccupied only with the spread of modern Western culture throughout the world, without recognising that the meaning of science changes across cultures and within cultures across time (Raina, 1999, p. 502). According to Raina, there are substantial historical evidences which show that "'more' non-European knowledge travelled to Europe than is often acknowledged" (Raina, 1999 , p. 502) and in the process of knowledge transmission "the periphery has been the source of important new ideas in the theoretical sciences" (Raina, 1999, p. 506). 


\section{Re-View from the Periphery}

It is very clear then that scholars are quick to identify the inadequacy in Basalla's thesis. In this scenario, a good many histories of colonial science and medicine in India come to enquire how the scientific ideas are circulated and raise several new questions. Despite differences between their respective points of view, they all suggest that the interminable story of the diffusion and absorption of modern science and medicine as only a Western cultural import is inadequate. It misses out the multifarious nature of transmission of knowledge between South Asians and Europeans. One of the pioneers in this genre, Deepak Kumar explores the intricate connection between imperialism and science and analyses the process whereby an 'alien' system of knowledge, methods and tools have truly become indigenised (Kumar, 1980; 1996; 2000; 2004; 2006). Although, Kumar's writings lavishly deal with various theories of diffusion and exchange, invoking such names as Basalla, Michael Worboys, MacLeod, Sangwan and Krishna, his empirical works often are not geared to the modification or advancement of such theoretical insights (Kumar, 1980, pp. 105-113; 2006, pp. 1-31). Elsewhere, Kumar showed that a number of European physicians visited pre-colonial India and wrote extensively on Indian disease condition and therapeutics. As they failed to develop a comprehensive aetiology of maladies, concluded that Indian diseases were environmentally determined and should be treated by Indian methods. They, however, continued to look at the Indian practices with curiosity and disdain, but regarding use of drugs Europeans and Indians both learned from each other (Kumar, 2001, pp. xvi-xvii; 2010, p. 263; 2011, pp. 236237). But during the high noon of colonial rule this type of 'synergetic' relationship between the 'micro-parasites' and the 'macro-parasites' was far more difficult (Kumar, 2001, p. xix). "There were several areas in which the western and indigenous system could collaborate but did not" (Kumar, 1997, p. 169). Moreover, as David Arnold pointed out, Western medical science assumed a position of superiority over indigenous medicine and 'native' bodies by which subject people and local medical systems were subjugated and marginalised and thus the possibilities of medical pluralism came to an end (Arnold, 1989, pp. 11-12; 2000, pp. 6667). However, recently in their edition, Kumar and Raj Sekhar Basu question the binary division of 'West' and 'non-West' and confidently argue that: "there is no 'pure' East, no 'pure' West... The word 'Western' in relation to medicine has, correctly speaking, no meaning. Science knows no geographical limitations" (Kumar and Basu, 2013 , p. 15) ${ }^{3}$. According to them, the exchange and adoption of knowledge are not something always imposed forcibly from above, nor these are osmotic transfers. They come from the logic of the interactions between the global and the local (Kumar and Basu, 2013, p. 8).

In recent year scholars also argue that, the cultural orientations and inner dynamics of the colonial periphery are important aspects to be noticed in the study of scientific transmission. Regarding this, Deepanwita Dasgupta writes: "the emergence and stabilization of a scientific culture within peripheral communities depend crucially upon their ability to solve some metropolitan problem and create a striking exemplar" (Dasgupta, 2009, p. 149). Whereas Kapil Raj seems to uphold the idea that the construction of scientific knowledge in the remote colony is a result of co-constructive process of negotiation between different skilled communities and individuals, and not just the result of a simple transfer of knowledge from the core (Raj, 2006; 2013). He, however, emphatically writes: "knowledges that thus emerged were totally

3. For a discussion on Western—non-Western medical categorisation, also see Ebrahimnejad, 2009. 
contingent on the encounter (between Europeans and Asians) and that important parts of what passes off as 'Western' science were actually made outside the West" (Raj, 2006, p. 223, parenthesis added). In this regard, Raj and his colleagues also emphasise on the role played by the 'go-betweens' to make and change the contents and the paths of scientific knowledge. According to them, it is the go-betweens, who played a crucial role in making sustained encounter and interaction across different cultures. However, the go-betweens are not just "a passer-by or a simple agent of crosscultural diffusion, but someone who articulates relationships between disparate worlds or cultures by being able to translate between them" (Schaffer, et al., 2009, p. xiv). The careers of the go-betweens thus help us to understand the history of manifold and heterogeneous orientation in the formation of knowledge spaces.

There are several other scholars who also engage themselves with the diffusionist history of Western science and medicine and admit that scientific and medical knowledge cannot simply be transferred without the knowledge itself being changed in the journey (Arnold, 2000; Baber, 1998; Kumar, 2012; Prakash, 2000; Sivasundaram, 2005; 2007A; 2007B). In doing medical history, Mark Harrison argues that Western medicine in India has its own typical uniqueness and cannot be considered merely as an annotation to the history of Western medicine in general. For instance, many Europeans engaged in medical enterprises in British India used their experience to challenge metropolitan orthodoxies. Therefore, colonial innovations by them are not only important, they also have formative influence upon the development of what is known as Western medicine (Harrison, 2001; 2005; 2009A; 2009B; 2010; 2012). Harrison's works also depict that the relationship of colonial practitioners with their colleagues and professors at home was far from subservient. They often rightly differed from eminent metropolitan scientists regarding important points of detail. Furthermore, European physicians also engaged themselves with provincial societies and 'marginal' individuals in colonial periphery and shared their respective views which extended the network of knowledge and made them transnational. According to Harrison, these connections of different provinces and networks of medicine prove that the simple use of conventional centre-periphery equation is problematic (Harrison, 2010, p. 11). Therefore, the interplay between the core and the periphery is not a simple process, rather: "There were a multiplicity of actors at both centre and periphery with responsibility for developing the colonial medical services" (Jones, 2004, p. 17).

Pratik Chakrabarti also devotes considerable effort to investigate the position of Western science in the relation between metropolitan methods and colonial practices. According to him, the emergence of European discipline in a strange and distant land like India meant experiencing new phenomena, examining new facts, and developing new hypotheses. "Such experiences added new dimensions to Western science" (Chakrabarti, 2004, p. 1). Science, as it travelled from one society to another, was thus transformed, redefined and perhaps dislocated. Chakrabarti recognises, however liminal and peripheral these development might have been, there were space and opportunity for creativity in the periphery which in turn influenced the world of science in the metropole. In this connection, he argues that, working at a distance from 'home community', individual colonial scientist got an opportunity to develop and articulate his new and distinctive insight without "fear of being crushed early by the critical competitiveness of the 'commonsense' conformism of a dominant group" (Chakrabarti, 2004, p. 34). In his recent work, while focusing on the different forms of medical knowledge in eighteenth-century West and East Indies, Chakrabarti claims that the tropical world and its resources provided the 
space where European surgeons were confronted with alternative worldviews and practices and had to accept many such alternatives. But he also emphasises that though at many levels the colonial and the metropolitan worlds were closely linked by means of various creative and eclectic scientific processes, the social, political and military realities of knowledge formation often deemed the knowledge systems of the peripherals as ineffective because they were not measurable by the standard of metropolitan practices (Chakrabarti, 2010).

\section{Concluding Remarks: A New Perspective}

Basalla's model is problematic in many ways. Basalla proposes a one-way transfer of scientific knowledge from its western origin to the rest of the world ignoring the enormous differences in background and experience among the variety of geographic locations. In identifying the so-called non-scientific society with the 'absence of modern Western science', he underrates the innate scientific traditions and practices that remained and sustained themselves for centuries in the colonial peripheries like India and China and also ignores their multi-faceted interactions with the newly emerged 'scientific' disciplines. Indeed, Basalla's model projects science "as the flag-bearer of the civilizing mission of the West, dissipating superstition and installing new technological systems over the old, primitive ones" (Bandopadhyay, 2010, p. 15). Therefore, this model fails to grasp the very nature of Western science and medicine as a means of social control over or cultural suppression of the so-called nonscientific societies as several later scholars have shown (Headrick, 1981). Nevertheless, for a certain period, Basalla's three-phase linear evolutionary structure has overwhelmed the history of science in non-western landscapes. Scholars following his framework characterises colonial science as intellectually dependent on the epistemology of imperial metropole.
Actually, there were layers and inconsistencies in the relationship between the East and the West and the canvas was so complex and intense that no single framework of analysis could suffice. There is no paradox that, the coreperiphery model had convincingly contributed to our initial understanding of colonial science and medicine in India. But now we should probe further. Today, as the distinction between the centre and the margin is more complicated and, as the capital becomes increasingly mobile and fluid, any unidirectional notion of the diffusion of science and medicine in the colonial periphery means radically undervaluing the criticality of the process of dissemination. Here lies the limitation of employing Basalla-like models. So, we cannot go with the theory of the simple linear transmission of the scientific knowledge to outside Europe, instead adopt the view of appropriation of scientific ideas and practices by the non-European periphery. Moreover, departing from so-called 'models',we rather go on to suggest that it is of prime importance to locate historically the particular character and sign of colonial condition within which knowledge derived from the West was transmitted. Indeed, the specificity of the colonial context created a congenial condition for new ideas to be generated - ideas which could not possibly have generated by the experiential context in the metropole. For example, the scientist and surgeons in the colony, who were the principle bearers of European science and medicine in India, worked in a unique natural landscape that enthused and enabled them to study the flora and fauna as well as record diverse indigenous scientific and medical traditions and then incorporate many 'new' knowledge and ideas into their own western practices. There is no doubt, colonial condition with abundantly available species and natural resources provided the opportunity to the scientists and physicians to develop a scientific perspective which was different from that in the metropole. In this scenario, 'diffused' knowledge, whatever may be its original 'Western' form and the idiosyncratic 
character of its vector, should become considerably hybridized because of its travel from the metropole and its initially bewildered perambulation due to exigencies in the 'alien' colony. Thus colonial condition actively operated as a vital agent in the creation of western science and medicine - an unavoidable tenet, a fascinating research idea, which till now historians either have ignored or not pertinently acknowledged. This should be considered as a genuinely historical approach in the study of colonial science and medicine in British India.

\section{ACKNOWLedgement}

I wish to convey my thank to Dr Sudeshna Banerjee of Jadavpur University, Kolkata, for reading carefully the earlier draft of this article and providing valuable insights. I also wish to thank Prof Deepak Kumar and Prof Dhruv Raina of Jawaharlal Nehru University, New Delhi, for making their various writings available to me.

\section{BiBLIOGRAPHY}

Adas, Michael. Colonialism and Science, in Helaine Selin (ed.), Encyclopaedia of the History of Science, Technology, and Medicine in Non-Western Cultures, Kluwer Academic Publishers, Dordrecht, 1997, pp. 215-220.

Arnold, David. Introduction: Disease, Medicine and Empire, in idem (ed.), Imperial Medicine and Indigenous Societies, Oxford University Press, Delhi, 1989, pp. 1-26.

Arnold, David. Colonizing the Body: State Medicine and Epidemic Disease in Nineteenth-Century India, University of California Press, Berkeley and Los Angeles, 1993.

Arnold, David. Science, Technology, and Medicine in Colonial India, Cambridge University Press, Cambridge, 2000.

Baber, Zaheer. The Science of Empire: Scientific Knowledge, Civilization, and Colonial Rule in India, Oxford University Press, Delhi, 1998.

Bandopadhyay, Arun. Introduction, in idem (ed.), Science and Society in India 1750-2000, Monohar, New Delhi, 2010, pp. 11-27.
Basalla, George. The Spread of Western Science, Science, 156/3775 (1967): 611-622.

Chakrabarti, Pratik. Western Science in Modern India: Metropolitan Methods, Colonial Practices, Permanent Black, Delhi, 2004.

Chakrabarti, Pratik. Materials and Medicine: Trade, Conquest and Therapeutics in the Eighteenth Century, Manchester University Press, Manchester and New York, 2010.

Chambers, David W., and Gillespie, Richard. Locality in the History of Science: Colonial Science, Technoscience, and Indigenous Knowledge, in Roy MacLeod (ed.), Nature and Empire: Science and the Colonial Enterprise, Osiris, second series, 15 (2000): 221-240.

Dasgupta, Deepanwita. Progress in Science and Science at the Non-Western Peripheries, Spontaneous Generations: A Journal for the History and Philosophy of Science, 3/1 (2009): 142-157.

Ebrahimnejad, Hormoz. Introduction: For a History of Modern Medicine in non-Western Countries, in idem (ed.), The Development of Modern Medicine in Non-Western Countries: Historical Perspectives, Routledge, London and New York, 2009, pp. 1-22.

Habib, S. Irfan, and Raina, Dhruv. Introduction, in idem (eds.), Social History of Science in Colonial India, Oxford University Press, New Delhi, 2009, pp. xiii$\mathrm{xl}$.

Harrison, Mark. Medicine and Orientalism: Perspectives on Europe's Encounter with Indian Medical Systems, in Biswamoy Pati and Mark Harrison (eds.), Health, Medicine and Empire: Perspectives on Colonial India, Orient Longman, New Delhi, 2001, pp. 37-87.

Harrison, Mark. Science and the British Empire, Isis, 96/1 (2005): 56-63.

Harrison, Mark. Medical Experimentation in British India: The Case of Dr Helenus Scott, in Hormoz Ebrahimnejad (ed.), The Development of Modern Medicine in Non-Western Countries: Historical Perspectives, Routledge, London and New York, 2009A, pp. 23-41.

Harrison, Mark. Racial Pathologies: Morbid Anatomy in British India, 1770-1850, in Biswamoy Pati and Mark Harrison (eds.), The Social History of Health and Medicine in Colonial India, Routledge, London, 2009B, pp. 173-194. 
Harrison, Mark. Medicine in an Age of Commerce and Empire: Britain and Its Tropical Colonies 1660-1830, Oxford University Press, New York, 2010.

Harrison, Mark. Networks of Knowledge: Science and Medicine in Early Colonial India, c.1750-1820, in Douglas M. Peers and Nandini Gooptu (eds.), India and the British Empire, Oxford University Press, Oxford, 2012, pp. 191-211.

Headrick, Daniel R. The Tools of Empire: Technology and European Imperialism in the Nineteenth Century, Oxford University Press, New York and Oxford, 1981.

Inkster, Ian. Scientific Enterprise and the Colonial 'Model': Observations on Australian Experience in Historical Context, Social Studies of Science, 15/4 (1985): 677704.

Jones, Margaret. Health Policy in Britain's Model Colony: Ceylon (1900-1948), Orient Longman, New Delhi, 2004.

Krishna, V. V.. The Emergence of the Indian Scientific Community, Sociological Bulletin, 40/1-2 (1991): 89-107.

Krishna, V. V.. The Colonial 'Model' and the Emergence of National Science in India: 1876-1920, in Patrick Petitjean, Catherine Jami and Anne Marie Moulin (eds.), Science and Empires: Historical Studies about Scientific Development and European Expansion, Kluwer Academic Publishers, Dordrecht, 1992, pp. $57-72$.

Kumar, Deepak. Patterns of Colonial Science in India, Indian Journal of History of Science, 15/1 (1980): 105-113.

Kumar, Deepak. The 'Culture' of Science and Colonial Culture, India 1820-1920, The British Journal for the History of Science, 29/2 (1996): 195-209.

Kumar, Deepak. Medical Encounter in British India, 18201920, Economic and Political Weekly, $32 / 4$ (1997): 166-170.

Kumar, Deepak. Reconstructing India: Disunity in the Science and Technology for Development Discourse,1900-1947, in Roy MacLeod (ed.), Nature and Empire: Science and the Colonial Enterprise, Osiris, second series, 15 (2000): 241-257.

Kumar, Deepak. Social History of Medicine: Some Issues and Concerns, in idem (ed.), Disease and Medicine in India: A Historical Overview, Tulika Books, New Delhi, 2001, pp. xi-xxii.
Kumar, Deepak. Emergence of 'Scientocracy': Snippets from Colonial India, Economic and Political Weekly, 39/35 (2004): 3893-3898.

Kumar, Deepak. Science and the Raj: A Study of British India, Oxford University Press, New Delhi, 2006.

Kumar, Deepak. Probing History of Medicine and Public Health in India, Indian Historical Review, 37/2 (2010): 259-273.

Kumar, Deepak. Adoption and Adaption: A Study of Medical Ideas and Techniques in Colonial India, in Feza Günergun and Dhruv Raina (eds.), Science between Europe and Asia: Historical Studies on the Transmission, Adoption and Adaptation of Knowledge, Springer, London and New York, 2011, pp. 233-243.

Kumar, Deepak, and Basu, Raj Sekhar. Introduction, in idem (eds.), Medical Encounters in British India, Oxford University Press, New Delhi, 2013, pp. 1-19.

Kumar, Prakash. Indigo Plantations and Science in Colonial India, Cambridge University Press, Cambridge, 2012.

MacLeod, Roy. On Visiting the 'Moving Metropolis': Reflections on the Architecture of Imperial Science, Historical Records of Australian Science, 5/3 (1982): $1-16$.

MacLeod, Roy. Reading the Discourse of Colonial Science, in Patrick Petitjean (ed.), Les Sciences Coloniales: Figures et Institutions, ORSTOM Éditions, Paris, 1996, pp. 87-96.

MacLeod, Roy. Introduction, in idem (ed.), Nature and Empire: Science and the Colonial Enterprise, Osiris, second series, 15 (2000): 1-13.

Prakash, Gayn. Another Reason: Science and the Imagination of Modern India, Oxford University Press, New Delhi, 2000 .

Raina, Dhruv. From West to non-West?: Basalla's Threestage Model Revisited, Science as Culture, 8/4 (1999): 497-516.

Raina, Dhruv. Images and Contexts: The Historiography of Science and Modernity in India, Oxford University Press, New Delhi, 2003.

Raina, Dhruv, and Habib, S. Irfan. Patronage, Competition and Rivalry: The Structure of Scientific Exchanges in the Age of Colonialism, in Patrick Petitjean (ed.), Les Sciences Coloniales: Figures et Institutions, ORSTOM Éditions, Paris, 1996, pp. 211-222. 
Raina, Dhruv, and Habib, S. Irfan. Domesticating Modern Science: A Social History of Science and Culture in Colonial India, Tulika Books, New Delhi, 2004.

Raj, Kapil. Relocating Modern Science: Circulation and the Construction of Scientific Knowledge in South Asia and Europe, Seventeenth to Nineteenth Centuries, Permanent Black, Delhi, 2006.

Raj, Kapil. Beyond Postcolonialism.... and Postpositivism: Circulation and the Global History of Science, Isis, 104/2 (2013): 337-347.

Sangwan, Satpal. Science, Technology and Colonisation: An Indian Experience, 1757-1857, Anamika Prakashan, Delhi, 1991.

Sangwan, Satpal. Natural History in Colonial Context: Profit or Pursuit? British Botanical Enterprise in India 17781820, in Patrick Petitjean, Catherine Jami and Anne Marie Moulin (eds.), Science and Empires: Historical Studies about Scientific Development and European Expansion, Kluwer Academic Publishers, Dordrecht, 1992, pp. 281-298.
Schaffer, Simon. et al.. Introduction, in idem (eds.), The Brokered World: Go-Betweens and Global Intelligence, 1770-1820, Science History Publications, Sagamore Beach, MA, 2009, pp. ix-xxxviii.

Sivasundaram, Sujit. Trading Knowledge: The East Indian Company's Elephants in India and Britain, The Historical Journal, 48/1 (2005): 27-63.

Sivasundaram, Sujit. 'A Christian Benares': Orientalism, Science and the Serampore Mission of Bengal, Indian Economic and Social History Review, 44/2 (2007A): 111-145.

Sivasundaram, Sujit. Tales of the Land: British Geography and Kandyan Resistance in Sri Lanka, c. 1803-1850, Modern Asian Studies, 41/5 (2007B): 925-965.

Worboys, Michael. Colonial and Imperial Medicine, in Deborah Brunton (ed.), Medicine Transformed: Health, Disease and Society in Europe, 1800-1930, Manchester University Press, Manchester, 2004, pp. 211-238. 